\title{
Strategic Human Resource Management for the Technology Innovation for SME’s In Korea
}

\author{
Jinwoo Yang \\ Hanyang University \\ Gyunghyun Choi \\ Hanyang University
}

\begin{abstract}
These days, technology is considered as a national source to make growth sustainable. In this sense, many countries support enterprises to innovate and upgrade their technological capabilities. However, for SME(small and medium-sized enterprise), it is difficult to achieve the desired outcome from the government support. We understand that one of main reason is the problem of human resources of SMEs. Comparing to large scaled enterprises, SMEs have relative weakness not only in the recruiting of talented new personnel but also in the retraining of existing workers. In this study, we propose a technological human resource management (HRM) model in conjunction with a technology strategy model as well as some strategic guidelines for HRM for the technology innovation of SMEs. This proposed model focuses on motivation of existing workers for technology innovation, with the findings through case studies of some SMEs that are successful in the HRM for technology innovation. The proposed guideline will be useful to managers who are responsible for technology innovation in SMEs and also will be helpful to SME-policy makers of government.
\end{abstract}

Keywords: Human Resource Management, Technology Strategy, Small-and-Medium Sized Firms, Technology Innovation

\section{Introduction}

\section{Relationship between outcomes of organization and $R \& D$ human resource management}

There are numerous research works that insisted on importance of $R \& D$ human resource management (HRM). Among them, we are focusing on some modeling approach ones. Allen et al. (2003), Bae et al. (2003) and Collins and Smith (2006) analyzed how the R\&D HRM affected the outcomes of the organization through employees' contribution to the organization. They assumed key factors for successful HRM such as high salary policy, performance based evaluation, educational training, and employment stability. And they analyzed relationship between these factors and organizational performance. Also, Bae and Sa (2003) proposed a model to verify the effects of HRM to the outcomes of organizations. 
They found the outcomes came from an organization finally affected some aspects of customers and finance, and hence they insisted that HRM of an organization is an important factor to the organization performance by providing the positive relationships between HRM and the outcomes of the organization. Moreover, Kim and Cho (2008) suggested a twodimensional model which explained that HRM affected firstly the outcomes of it directly and finally the performance of the organization.

These previous studies are all about strongly positive relationship between organizational outcomes and R\&D human resource management. More specifically, these studies are not just simple linear theories which claim organizational performance directly connected to human resource management, but more intricate ones that indicate better $\mathrm{R} \& \mathrm{D}$ professional management produce better outputs of human resource management itself, and furthermore, better outcomes of the whole organization. These results are all related to the theory of Becker (2001). Becker(2001) suggested a causal relation that human resource management system affects employees' behaviors that make strategies of corporate feasible, and performance of the management would ultimately encourage the higher outcomes of the whole company. Similarly, Wright et al. (1999) also argued that human resource management didn't affect the organizational outcomes directly, but it gave influence through the employee outcomes.

\section{Government Support Programs for SMEs’ R\&D Human Resource Management}

Having recognized the importance of $R \& D$ human resource management as well as its outcome, in Korea policies for personnel recruiting along with its development and management is being managed. Such human resource policies are usually divided in to two periods and at the moment we are in the midst of the second phase from 2011 2015.

The second phase focuses mainly on the policies of small and medium sized firms taking the human resource supply and training support into consideration along with numerous other factors such as awareness-raising, strengthening of information offering, working and welfare environment, job creation, system reorganization and more. The 20 or more work policies of small and medium sized businesses can be classified as follows:

First, high school and college students specializing in Design are able to participate in small and medium-sized firms by utilizing the Solution program. By having students involved in the company's vocational training, students are provided with work experience as well as job opportunities.

The second policy group preferentially offers national public housing to non-homeowners within the company. Moreover, it goes on to provide partial support for the labor costs of experienced technical human resource as well as those holding a masters degree in either natural science or engineering. It also supports the labor cost of retired scientific technicians, additional aid in deploying foreign science technician of a global level into domestic research development sites and finally scouting of highly talented foreign individuals. There exists an additional support in which medium-sized companies can utilize research staffs of the government-funded research institute for more than three years.

The third one helps to train technical professionals for specific type of business, called the green technology. Additionally, it provides education to enhance the occupation abilities of the firm's current workers as well as managing a separate department of its own to induce a long-term employment and further enhancing vocational abilities. Finally, setting the 
employment of medium-sized firms after graduation as its ultimate goal, the particular system allows for a training of professionals by signing an agreement and collaborating with schools and students.

\section{Assessment of Korean SMEs’ R\&D human resource management}

Recently, Korea Industry Technology Association (KOITA) took a survey of 12,064 corporations that hold either 'enterprise institute' or 'research and development department' and carried out government's R\&D projects for over 3 years. Respondents answered that tax advantages and labor force supports are the most influenced out of all government's support systems. Especially, among every human resource support system, Employment Encouraging Programs and Professional Supporting Programs (one of the Korean government support programs) for high skill researchers are known to be most attractive. Also, $41.6 \%$ of respondents answered that support for human resources were significantly helpful regardless of the size, type, or location of the companies, while $51.8 \%$ declared as helpful to only a certain degree. In any case, we have seen that shortage of professional technology human resources was still the biggest difficulty for technology innovation activities. From another survey for future R\&D investment, we were told that $66 \%$ of respondents would increase their R\&D investment compared to previous year, while $30.7 \%$ of respondents would remain as previous year. Only $2.7 \%$ stated that they will decrease their R\&D investment.

Figure 1. Assessment of Korean SMEs’ R\&D human resource management

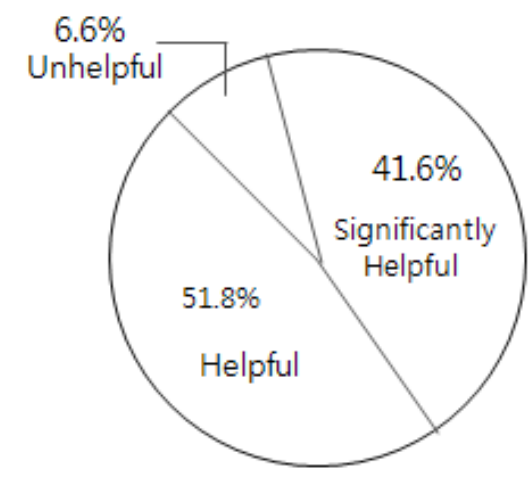

Effect of government's support policy for human resources management

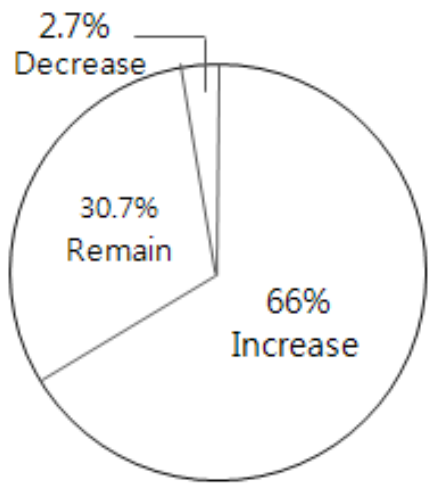

The trend of R\&D investment compared to previous year (2011)

Also, 49.3\% declared that of major considerations of SMEs' R\&D were about securing and managing human resources, and among them, $47.6 \%$ complained of shortage of skilled people for their R\&D activities. Throughout the surveys, we have seen that government's R\&D human recourses support systems had been effective for SMEs, but SMEs would have severe difficulties for securing and managing human resources regardless of growing $R \& D$ budget. What we understand is not simply about increasing R\&D budget but 'human resource' and 'management' issues which can lead money flows.

\section{Research Objectives}

In this research, what should be focused is the key connection in progressing steps of behavioral change of employees that started from R\&D HRM to employees' outcomes and 
from employees' outcomes to outcomes of organization. This can be treated as 'technology strategy'. Wright and Boswel (2002) proved that suitability between human resource management and technology strategy should be set in the process starting from HRM to the outcomes.

As mentioned earlier, plenty of studies proved positive effect of HRM to organizational outcomes, along with the suitable relations with technology strategy. In order to understand more specifically, however, how technology strategy should be connected to HRM and how HRM should be delivered in each step of carrying out technology strategy still needs to be discussed. Based on the facts and preceded studies, if enlargement of R\&D investment could give positive influence to the outcomes of corporations is what really matters, not the actual fact that SMEs are simply paying attention to R\&D. Technology takes a large portion when establishing and performing technology strategy, but environmental feature of nontechnological factor which is the 'strategic will' is the most important thing in the aspect of direction. The environmental feature of non-technological factor is harder to be digitized than the other conditions which decide technological direction mentioned above, and it could be the reason that might break the market forecast.

\section{The Proposed Model In Conjunction With Technology Strategy}

In performing step of technology strategy, Rothwell and Zegyeld(1985)'s 'Coupling Model of Innovation' would be applied for further study.

Figure 2. A benchmark technology management model (Adopted form Rothwell and Zegyeld, 1985)

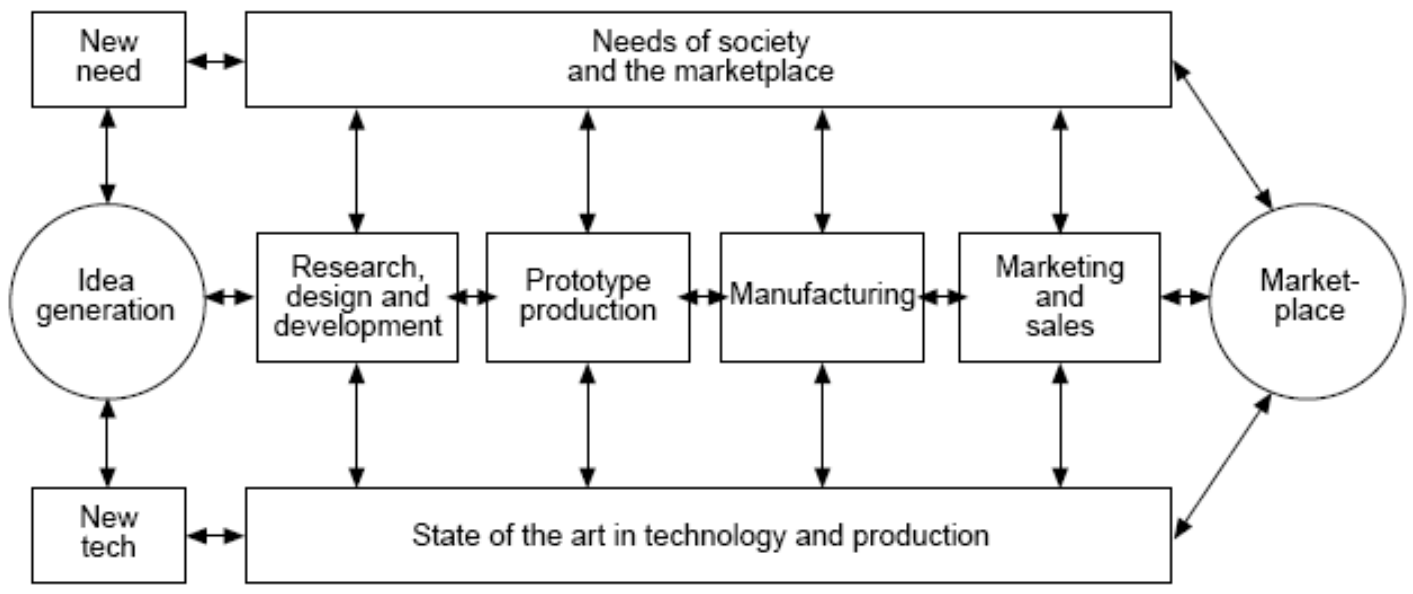

Note that either technology or the market appears to be more significant in stimulating invention but this model insists that the majority of innovations involve a creative coupling of technological and market factors. Failure may arise from not only getting the technology right but also from misjudging the market. Success is more likely if the focus is not onedimensional but rather a balance between technology and market considerations.

But a key challenge with invention and innovation is that both technology and the market are changing continuously. What is technically unachievable today may be possible in a few years time due to scientific advances, sometimes in an unrelated field. Likewise what cannot be sold today may come to be regarded as a necessity by future consumers. 
The skill of operating at the interfaces between advancing technology and changing market is to make the connection between technological and market possibilities. It can be a creative process similar to the associative thinking involved in the original invention itself, and is often the province of the entrepreneur.

This coupling between technology and market needs is important at every stage of the innovation process, from the first flash of inspiration, through the entire research, design and development work to the introduction of the new product or process onto the market.

Although the innovation process clearly contains technology and market elements, any model of the process has to introduce some sense of interaction and growing complexity. It must have feedback loops and a variety of links both between science, technology and the market place, and between innovating firms and the outside world. With the coupling model, we propose R\&D HRM model that consider technology and human resource management explicitly

Figure 3. The R\&D Human Resource Management Model within Technology

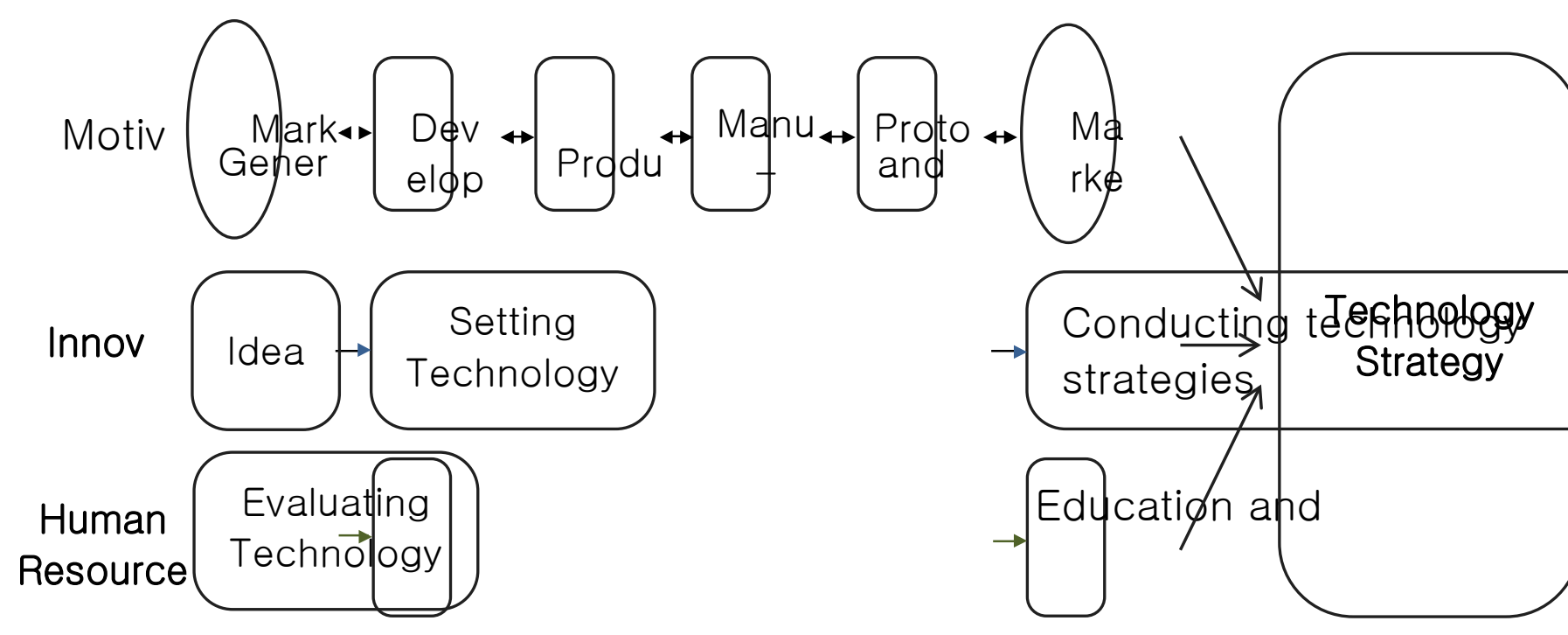

This model focuses on connecting factors of the coupling model namely, technology strategy, and technology professionals. Technology innovating steps is made of 5 steps for market release, which includes idea generation, development, prototype production, manufacturing, marketing and sales.

Technology strategy is established in idea generation step, and established technology strategy is performed in development, prototype production, manufacturing, marketing and sales step. Technology strategy which is performed in this way is released to the market and is evaluated through market response. Motivation, education and training, HRM which includes feedback and compensation is focused in each establishing step along with all the steps of technology strategy, performing step, and evaluating step. The proposed model could act importantly especially to SMEs in Korea.

In case of Korean SMEs, CEO could manage the company directly like the own family because all of the details of employees can be known. As a result, the importance of suitable structure of organization or culture settlement for R\&D professionals' leadership, technology innovation, and carrying out technology strategy is often easily ignored. When SMEs becomes larger and the one who can carry out technology strategy in this state, another problem related to R\&D human resources' 'strategic will' could be aroused. In other words, 
the possibility of lower suitability in connection between technology strategy and HRM becomes higher.

Furthermore, although current $R \& D$ costs are increasing, it is difficult for SMEs to recruit professionals that could perform those activities effectively, and this becomes the main cause of failure of technology development and market failure. Eventually, the problem of innovating technology professionals and absence of management would become serious.

\section{Case Studies For Execute Process Of Technology Strategy And Hrm}

\section{Case of Company A}

Table 1. Summary of Company A's Research \& Management

\begin{tabular}{l||l}
\hline Product Name & Banknote counter \\
\hline Product Purpose & $\begin{array}{l}\text { Identifying the kind of copy of a product and detecting counterfeit } \\
\text { note }\end{array}$ \\
\hline $\begin{array}{l}\text { Period } \\
\text { Development }\end{array}$ & $\begin{array}{l}\text {-Research and Development: 2006.12 2008.9 } \\
\text {-Commercialization: 2009.9 2009.12 }\end{array}$ \\
\hline
\end{tabular}

\section{Performing Steps of technology Strategy}

(a) Idea Generation Since high-denomination banknote has been issued and the most advanced device for making counterfeit banknote has been developed, the possibility of distribution of counterfeit banknote has surged high. This caused market to ask for more accurate device to detect counterfeit banknote immediately. Fake note is usually detected by finding fluorescence materials or infrared rays ink pattern of a note with sensors such as infrared light (IR), magnetic (MG), ultraviolet rays (UV), fluorescence (FL), or applying magnetic field property. This way, however, is not desirable when detecting perfectly faked notes or super note because it doesn't use note penetrating property, only using light's reflecting characteristic.

One-pocket compact banknote counter, which was the device banks were using at the time of research, was known to have decreased ratings of detecting fake notes. Also, it got more difficult to detect accurately as advanced technology of tape manufacturing made tapes thinner even though damaged banknotes with a tape are needed to be filtered strictly. Finally, company A suggested developing new two-pockets subcompact banknote counter of counting and detecting function and also another function that is to save the bills into specially separated pocket once the note is put.

(b) Development The company paid attention to the fact that existing devices mostly detect a note by reflecting only one side of the note. Therefore, it designed fake note detecting method by using ultrasonic waves' penetrating property and applying ultraviolet rays, magnetic, or infrared light thoroughly. This made it possible to detect damaged notes by knowing thickness or material qualities of a note.

The company took drawing patent map in priority, checked global level of technology and patent infringement avoiding skill, searched technology acquiring process of rival company, and set a strategy to get license.

It afterwards defines a core technology for analyzing ultrasonic waves, wave patterns, or wave locations of a tape copy. This technology for detecting fake note by using the medium's ultrasonic waves is based on the fact that patterns of ultrasonic waves are not all the same. Wave patterns included in a tape of a tape copy could also be analyzed. 
(c) Prototype \& Manufacturing First difficulty faced to this company when developing a prototype based on core technologies defined above. There was no example for company to refer because this company firstly used ultrasonic waves in the country. Also, the problem of interference between ultrasonic waves sensor was serious because echo of ultrasonic waves stays relatively longer unlike light sensor. Eventually, the best combination was drawn as a solution to the problem after experimenting hundreds of combinations between fifteen ultrasonic waves' sensors. This is acquired after making and installing dozens of sensor modules and equipment.

(d) Marketing \& Sales The product of this company was examined by mass-production department before releasing to the market. Then, mass-production unit, which is in between the R\&D unit and manufacture unit took tests to check if manufacturing process is being progressed in the customers' point of view by following the result of research and development. The test taken by mass-production department reminds that it is customers' opinion that matters when setting plans for marketing and selling.

\section{Managing technological professionals}

(a) Setting technology strategies: Motivation Two-pocket banknote counter of the company was a project started in the middle of progressing other project after realizing technological need. Although it took huge costs and time for that project, management's constant support for expenses and faith in developing professionals became a motivation to boost them. Connection and Development (C\&D) mind of the company, along with material support, also became the opportunity for employees to communicate continuously. Sharing information by communication between employees in the company was even smoother because of the program 'Bizmeka'.

(b) Conducting technology strategies: Educating \& Training In the development stage, the company has already realized the importance of 'patent', and placed special professionals for patent apart from developing professionals. Also, education from outside and programs for promote special experts was carried out so that technology developers can have professional knowledge. Furthermore, patent consulting expert was invited from the outside to have educational programs for whole $\mathrm{R} \& \mathrm{D}$ units twice a year, and the company sought for the way to avoid rival's technology or invalidate rival's patents by participating patent risk consulting abroad.

(c) Evaluating technology strategies: Evaluation \& Compensation The outcomes of the company was evaluated by making researchers write their business logs and indicating their achievements and results with numerical figures. Heads of departments and laboratory chiefs who were reported set the payment of incentives differently based on the assessment of whether the objective was achieved or not by comparing each researcher's working plan and result of it. Strangely, they had to evaluate their own capability by themselves.

Also, project managers held group or personal meetings once a week at a fixed time, and released the problems that were mentioned during the process of performing technology development or working progress of each person to a whole server. This is a kind of a feedback that can catch how much other researchers have developed so far or what kind of problems they have, share the bond between them about their works, and avoid any conflict of opinion. 


\section{Case of Company B}

Table 2. Summary of Company B’s Research \& Management

\begin{tabular}{l||l}
\hline Product Name & label for electronic tag producing device with flatbed cutter \\
\hline Product Purpose & $\begin{array}{l}\text { produce electronic label, tag, card, ticket by laminating or die } \\
\text { cutting RFID Inlay to the fabrics such as thermal paper, coated } \\
\text { paper, or synthetic paper }\end{array}$ \\
\hline $\begin{array}{ll}\text { Period } \\
\text { Development }\end{array}$ & R\&D and Commercialization: 2005.05 2009.07 \\
\hline
\end{tabular}

\section{Performing Steps of technology Strategy}

(a) Idea generation The company under the circumstance of ubiquitous which expanded its usage from fixed type RFID into mobile type RFID and of RFID/USN. The government was also demanding to build RFID related system for synthesizing surroundings. The problem, however, was that it was impossible to produce RFID smart label inexpensively which should be attached to every product even after RFID system is successfully built.

The company had manufacturing know-how of label printing device called 'Rotary' which is firstly developed in the country. This technology, however, was for general printing and new project for the development was planned on the purpose of manufacturing RFID smart label with converting device.

(b) Development Product development started from making converting device the company firstly got the video about that device by contacting other country's manufacture company agency in the country at a national RFID fair. The company tried to understand the principles by reviewing the video and gathered information even by visiting related manufacturers in Germany. Even in Germany, however, there were only 3 RFID converting device manufacturers, and it was impossible to see the actual manufacturing process because those companies were highly conservative. Therefore, this company had to gather as much information as possible by seeing the exterior of completely manufactured products and finding answers to their questions on their own.

(c) Prototype \& Manufacturing Two kinds of core technologies were defined in the process of information gathering, and those two refer to technology which has been already possessed and technology which needs to be developed. Technology to device electric control and operation is already in possess while the technology of motion control of servo motor is not in possess and therefore needs to be developed. Especially, it was important to handle servo motor precisely because each servo motor of each product was differently designed. The company selected a German institute that had high quality reliability and many customers, asked for a design engineer and started cooperation, but the contract was expired even before it obtains related skills completely. Eventually, it started to develop its own technology.

(d) Marketing \& Sales The company officially commercialized its technology by applying to the actual manufacture of RFID label to secure effectiveness and reliability of the device. In that process, however, various difficulties occurred. Firstly, problem aroused during the production stage. It was possible for built in chip to be damaged by the condition 
of a chip in the RFID antenna during manufacture process of device, and even worse, it was hard to check how much it was broken. Also, the quality difference of each cooperative inlay manufacturer was also the problem to be solved. In order to solve these difficulties, selfmanufactured inlay was resulted not being controlled by the quality of inlay but confirming disadvantages in more detailed way.

Lastly, the durability of components became the problem. This is caused by making a mistake to applying the standards offered from component manufacturers as they are when predicting of exact persisting period of consumable supplies. The company considered this not as manufacture's fault but as 'its flaws'. The company analyzed each part structurally and solved its device problems by itself finally became the advantageous feature for the company when introducing the device to its customers.

\section{Managing technological professionals}

(a) Setting technology strategies: Motivation The company asked for a teamwork to German company for related technology to understand the construct of advanced device which is a standard to selecting main components. Under the confused circumstances without any expert, it tried to realize effective motivations by making a development contract with special engineer from the outside. Also, it also tried to build background for technological innovation for longer services.

(b) Conducting technology strategies: Educating \& Training Inviting the special engineer from the outside could also mean that the process of obtaining new technology was also done based on possessed technology by cooperating and sharing with the experts. This offered a chance for researchers to naturally internalize the technology they are about to develop, and active gathering of information through visiting abroad and materials from the other countries became the opportunity for wider education. Furthermore, it built cooperative relationship with universities that have theoretical background and considerably high capability of components development so that it could get help when developing RFID reader module for its own device and specializing its performance. Keeping collaboration by constant personal exchange or technology exchange for R\&D of new technology was one diversified kind of way for researchers to obtain new technologies.

(c) Evaluating technology strategies: Evaluation \& Compensation Evaluation for works was conducted once a year, but it was not independent but total of which result could affect the compensation for researchers.

\section{Organizational Outcomes of Business Cases}

Based on the model proposed in earlier, companies gained the results of technology strategy and the outcomes of the organization through the connection between technology strategy and human resource management. Their outcomes can be understood more clearly by systems and rewards program from Korean government

(a) Small and Medium-sized Business of Technological Innovation: It refers to a group of companies that have stable growth and more than 3 years of experiences of technology innovation, and that are capable of securing global market competitiveness by constant technology and value innovation. The name of this program is also called to Inno-biz program

(b) NET(New Excellent Technology Authentication): It is to certify institutionally the newly developed good technology in the country. 
(c) NEP(New Excellent Product Authentication): It is to certify product which has newly developed technology in the country or alternative technology of similar qualities, or to support early stage of pioneering the market and promote further technology development.

(d) IR52 Jang Young Sil Award: It is an award for technology developer in domestic manufacturers or research institutes that led industrial technology innovation by developing and commercializing products of new technology.

Especially, when it comes to the cases of 'NEP' or 'IR52 Jang Young Sil Award' among four selecting standards or when the company actually developed new technology in commercializing level, aspects of commercialization or value convey to customers are considered significantly. In other words, it could be said that corporate performance can be attained from right connection between technology strategy and technology professionals management.

Companies which were selected by these standards are shown in Table 3.

Table 3. List of Awards which Company A and B were received

\begin{tabular}{l||l|l}
\hline Classification & $\begin{array}{l}\text { Main Product } \\
\text { and Field of study }\end{array}$ & Awards \\
\hline \hline & -Financing office Device \\
Company A & IR52 Jang Young Sil Award (2010) \\
\cline { 3 - 3 } & -Communication Device & $\begin{array}{c}\text { Small and medium-sized business of technol } \\
\text { ogy of innovation (2009) }\end{array}$ \\
\hline \multirow{2}{*}{ Company B } & -Price indicator, Label & $\begin{array}{c}\text { IR52 Jang Young Sil Award (2011), NEP (2 } \\
\text { 006) }\end{array}$ \\
\cline { 3 - 3 } & -Office device & $\begin{array}{c}\text { Small and medium-sized business of technol } \\
\text { ogy of innovation (2006) }\end{array}$ \\
\hline
\end{tabular}

\section{Conclusion}

\section{Summary and Analysis}

Companies which were studied so far succeeded in technology development by technological innovation, planning the best strategies, and performing human resources management. Also, they achieved NEP and were awarded IR52 Jang Young Sil Award. Core things about companies of case study are shown in Table 4. 
Table 4. Core activities about Company A and B

\begin{tabular}{l||l|l}
\hline & Company A & Company B \\
\hline \hline Motivation & $\begin{array}{l}\text { Communication: Bizmeka } \\
\text { Sharing information: C\&D (Conn } \\
\text { ection and Development) mindset }\end{array}$ & $\begin{array}{l}\text { Technology related culture: } \\
\text { securing technology engineer, } \\
\text { outsourcing } \\
\text { Technological innovation culture: } \\
\text { longer services }\end{array}$ \\
\hline \multirow{2}{*}{$\begin{array}{l}\text { Education } \\
\text { \& Training }\end{array}$} & $\begin{array}{l}\text { Education for patent } \\
\text { inviting patent experts from the } \\
\text { outside thecial professionals, } \\
\text { - Education for patent risk from abr } \\
\text { oad }\end{array}$ & $\begin{array}{l}\text { Obtaining technology } \\
\text { collaboration } \\
\text { Education by gathering information } \\
\text { from other countries }\end{array}$ \\
\hline $\begin{array}{l}\text { Evaluation } \\
\text { \& Compensati } \\
\text { on }\end{array}$ & $\begin{array}{l}\text {-Researchers' business logs, } \\
\text { indicating acquirement and results } \\
\text {-Evaluation from superiors, direct as } \\
\text { sessment }\end{array}$ & Work evaluation of once a year \\
\hline
\end{tabular}

By this result, software support such as communication, sharing information, or making technology related culture was suggested as a part of motivation, while support for hardware aspect was inadequate. Also, education for patent, which is to realize the value of intellectual property by connecting technology strategy and patent strategy, could end up by short education only for development for new products during projects. Lastly, when it comes to evaluation and compensation, phased evaluation or self-assessment of researchers themselves were done, but these were likely to rely on simple way only pointing out the gap between the outcomes and the original plans or on work evaluation for each department which is done just once a year.

\section{Implications}

\section{Building motivation related human resources system}

Most of the SMEs could continue the researches only when they are able to get money support from the management or when researchers make work plans out every year because of excessively high R\&D costs. This could be clearly noticed when compared to the case of Hyundai Motor Group which is one of major companies.

Hyundai Kia Motor Group has been holding ‘Research Committee System’ since 2009. This system aims at supporting excellent experts of certain field to concentrate to their studies without any concerns. After drafting excellent professionals among all of the $R \& D$ employees, special budget for their projects and incentives for their achievements are offered. This is to make good atmosphere for the research by motivating and encouraging strategically researchers to have willpower or creative ideas. It is true, however, that SMEs are incapable of offering such systematic supports shortly just like major companies. Therefore, support for hardware such as building a system for HRM is additionally needed to be offered 'simultaneously' along with the support for software, which is already being given in sample companies. 
This system of both aspects is meaningful because it can motivate human resources who are performing technology strategies set by company and it also invigorate the link between technology strategy and HRM.

\section{Continuous Education}

In education and training stage, one-off education only for one project or education just for short period was mainly carried out. SMEs' educational support is much scarcer than major companies' or government-funded research institutes' even though $90 \%$ of research institutes in the country and $60 \%$ of research professionals in the country belong to small and mediumsized business in 2009.

Company B, which obtained advanced technology from the outside by an open innovation approach, might lose its opportunities for constant education and training once the project of related technology strategy came to an end. Therefore, a systematic support for longer education and training is needed. Doosan Electro-Materials, which is one of major groups, runs one-stop system to constantly obtain knowledge for new patents from research reports, academic journals, technologies or advanced information.

Furthermore, education and training courses for obtaining technology should be diversified, and collaboration with universities or research institutes which was tried by Company B is one good example. Technology acquisition through cooperation with outside research institutes or universities can be effective because it is also a possible way for $R \& D$ professionals to develop their careers. Constant offering for educational opportunity becomes a positive feedback in technology strategy establishing cycle along with the technology strategy execution which is now in progress.

\section{Various Evaluations for each Project}

Evaluations for results were likely to be done in fragments or ineffectively. The productivity of $R \& D$ is generally hard to be measured, and it is difficult to predict the result of R\&D. Also, commercialization takes huge amount of time. Therefore, setting suitable evaluation index should be in priority, because this can make various evaluation models for each different project.

Secondly, the evaluation should be done in every step, not to mention right after all of the strategy steps were performed, even in the step for technology plan or technology strategy with the purpose of securing close connectivity between R\&D strategies and each project. This can be also effective to check the balance between technology strategy and each project, priority order of R\&D investment, current conditions, and application of available human resources.

Lastly, evaluation should be done thoroughly when evaluating the completion considering details such as project's accomplishments compared to objectives, suitability of performing period, applicability of invested budget, final performance, contribution level for the business, and resources distribution.

In this step, it is possible not only to compensate technology professionals for their successful performance but also to check the balance between technology strategy and the project, and meaningful outcomes could be delivered in the aspect of corporate management.

\section{The proposed model utilization plan}


Then, lets step forward and look into the government support programs of not only the firms examined in the case study but also of Korean medium sized companies introduced prior to the proposed model.

The first Korea's support programs mentioned earlier on (which supports design plan as well as providing young students with an experience at medium-sized companies) does not bring forth any direct benefits to the firm. Despite this, the aim of this system lies in offering students with work opportunities while simultaneously alleviating the students' pessimistic understanding of small and medium-sized companies.

The second one (offering housings to current firm employees, recruiting of both domestic and foreign top-level human resources and supporting labor cost of retired scientific technician) is for the most part in favor of the firm's current workers, hence acting as a key motivator of the $\mathrm{R} \& \mathrm{D}$ research. This is primarily done through the facilitating of the firm's influx of workers as well as aiding firms when undergoing difficulties recruiting foreign human resource along with those acquiring a master’s degree in either natural science or engineering.

To sum up, attracting and supporting the human resource elevates the worker's motivation, which in turn shapes the whole system as a key motivator for the proposed model.

Lastly, the third system (regarding the provision of green technology related education, support for the workers' post graduate studies) require a sophisticated knowledge of the given technology along with training programs to enhance the labor's work abilities. These criteria help shape itself as the education of the proposed Model.

Having examined the various human resource management systems existing today, it could be seen that most systems focus on the motivation and education of proposed models. Therefore, although firms are constantly endeavoring to manifest ideas, create technical strategies and putting them in practice, the development and strategy performance of the given technology after its release is solely reliant of the firm's own personal level.

Furthermore, Motivation is limited to the "top level human resource" we are able to work with, while education \& training is also restraint to the basic education of current human resource and finite education of professional skills rather than focusing on the development, prototype production, manufacturing, marketing \& sales.

When gathering such facts, it can be seen that the introduction of the proposed model will not only find itself useful in businesses, but also in arranging the government policies aim at supporting the R\&D business of smaller firms.

\section{Implications for Business Marketing Practice}

The message directed to the market practitioners regarding the proposed model and its detailed process is as follows. However, before we begin exists one particularly expecting response. When generally looking over the construction of human resource management regarding motivation, continuous education and the various evaluations of each individual project, it can be seen that such factors are more relevant to the technical human resource rather than the marketing responsible labor. In short, Market is a section which shapes its territory outside of a company, whereas the series of process; motivation-educationevaluation is established within the firm's inner territory. This allows us to deduce that the link between internal and the external fragments is very frail. Such cause of concern can be swept off through the accompanying reasons. 
First of all, a long-term technology strategy should be considered as it will create the core basis of the manuscript's proposed model. The fulfilling of technological strategies commences after numerous ideas have been manifested, as then technological factors will be required. This step is called the Idea Generation and Development process. The technological strategy then surpasses production stage and reaches its optimum during the final release of the product. Hence, outputs of revolutionary concepts are not simply about the technical skills, but more about the values earned through consumer response. That is to say that the technological strategy is included in every stage of production commencing from the development of the technology itself to the product's final release. It is for this reason, technical human resource management, as part of the technological strategy can help create an optimistic impact on the market.

Second, even within the marketing process, the steps of technical human resource management; motivation, education and evaluation find itself crucial. Having examined the various cases of corporations, it turned out that technical human resource management of marketing and sales phase is also persisted through the process execution of technological strategies. In the case of A corporation, the company introduced a phase where the human resource was specifically trained to compare the research and development results of the $\mathrm{R} \& \mathrm{D}$ team and the production team with the consumer response after which the correlation between the two were to be tested. On the other hand, B corporation decided to resolve the progressive issues regarding the RFID Label emerged in the midst of technological commercialization, as well as Inlay company's distinctive quality and component durability issues through the technological attempts of the firm's internal human resource. The fact that outbreaks of various complications could be dealt with internally without additional support allowed for a faster market release and response ability compared to other competitors.

We are heavily convinced that such background was only possible through the motivation, education and corresponding evaluations of the human resource beginning from the technology manifestation stage.

Lastly, the instance companies all have something in common. They all consist of market dominance, which they utilize to capture the competitive market. When concentrating on the marketing section and judging the success or failure of a particular technology, there is no better criterion than judging the company's market dominance. Such judgment could be determined through the instance companies' organizational achievements. It should be especially noted that in addition to the companies' highly praised technology behind their developed products, they have also been praised for their technological commercialization, hence receiving positive response from the market. In conclusion, the reasons mentioned above helps to once again emphasize that human resource management takes on a consequential role within the marketing section and that therefore the dissertation written by the market practitioners as well as their proposed model should be revised.

\section{Limitations and Future Research Plans}

In this study, the management of technological professionals which stimulates strategic mind was mainly studied along with the level of performance of technology strategies by researching SMEs' successful management of technology.

It was difficult to prove appropriate causation between technology strategies and HRM or strategic will because subjective aspect of researching two things of the latter was not 
avoidable. Also, corporations' sample was not enough because studied cases were either selected or judged independently.

Case studies which were carried out during the research would provide the chance to pay attention to the relationship between strategic mind and the interest about strategic human resources.

It is the fact that positive effects could be seen when HRM is connected to technology strategy that matters. Also, we can realize through suggested model that technology strategy should be considered carefully even from establishing step along with the HRM in order to make actual outcomes for the companies in Korea. How the human resource should be managed in each performing step would also be offered. Furthermore, analysis for current events which was mentioned earlier suggests the directions both for the models to connect more systemized technology professionals to technology strategies and for the SMEs.

Furthermore, it would also offer a chance to consider SMEs' technology strategies related fundamental concerns which are about declining or stagnant level of technology or capability of commercialization despite increasing $R \& D$ investment which is caused by high expectations for technological development. Additionally, it would be the opportunity for advanced future research by suggesting non-technological features, profits of technology or its relationship with business performance, and evaluation model methodology for management of technological professionals. Hence, through this analysis we were able to overlook the various ways government policies could create effective $R \& D$ progress of medium sized firms.

\section{References}

Agarwala, T. 2003. Innovative Human Resource Practices and Organizational Commitment: An Empirical Investigation. International Journal of Human Resource Management, 14: 175-197.

Allen, D. G., Shore, L. M., and Griffeth, R. W. 2003. The Role of Perceived Organizational Support and Supportive Human Resource Practices in the Turnover Process. Journal of Management, 29(1): 99-118.

Bae, J. 1999. Competitive Advantage and Human Resource Management: Beyond Strategic Human Resource management. Research on Human resource and Organization, 7(2): $1-45$.

Bae, J., Chen, S., Wan, T. W. D., Lawler, J. J. and Walumbwa, F. O. 2003. Human Resource Strategy and Firm Performance in Pacific Rim Countries. International Journal of Human Resource Management, 14(8): 1308-1332.

Bae, J. and Sa, J. 2003. The Effects of Human Resource Management Systems on Organizational Performance. Research on Human resource and Organization, 11(2) : 133-169.

Chiesa, V. 2001. R\&D Strategy \& Organization: Managing Technical Change in Dynamic Contexts. Universita degli Studi di Milano. Series on Technology Management, 5:6-8. 
Clark, K. B. and Fujimoto, T. 1991. Product Development Performance. Boston, MA: HBS Press.

Collins, C. J., and Smith, K. G. 2006. Knowledge Exchange and Combination: The Role of Human Resource Practices in the Performance of High-Technology Firms. Academy of Management Journal, 49(3): 544-560.

Hisatishi, Y. 2007. MOT Technology Strategy, Business School of WASEDA University, 3943.

Jang, E. 2007. An Advisable Evaluation System for Improve Business Performance. Korea Industrial Technology Association. Technology and Management, 12: 44-47.

Kim, C. 2007. Implementation of Research Management Systems and operation strategy. Korea Industrial Technology Association. Technology and Management, 9:45-48

Kim, C. 2009. A Study on the R\&D Human Resource Education and Methodology R\&D for Productivity Improvement. Korea Industrial Technology Association. Technology and Management, 8:42-43.

Kim, K. and Cho, B. 2008. A Study on the Relationships between HRM and Organizational Outcomes: Mediating Effects of Employee Attitudes an HRM Performance. Research on Human resource and Organization, 16(1): 115-157.

Kim, S. 2010. A Study on operational directions of Industrial R\&D centers: Company's Vision is Researcher! Korea Industrial Technology Association. Technology and Management, 1: 10-11.

Kwok, J. 2010. A Study on the Connection between Patent Strategies and Technology Strategies: New paradigm of IP Strategies. Korea Industrial Technology Association. Technology and Management, 11:12-15

Rothwell, R. and Zegveld, W. 1985. Reindustrialisation and Technology. Longman: Harlow.

Song, B. 2012. Research Outcomes and Tasks of Human Resource policy in Small and Medium Firm, Korea Institute for Industrial Economics \& Trade, Issue Paper 2012285:24.

Wright, P. M., and Boswell, W. R. 2002. Desegregating HRM: A Review and Synthesis of Micro and Macro Human Resource Management. Journal of Management, 28(3): 247-276.

Yang, B. 2009. The Exploration on the Core R\&D Employee Management, Korea Industrial Technology Association. Technology and Management, 11: 42-46

Yeon, D. 2010. A Study on Exploring for the Fairness of Evaluation and the role of R\&D Project leader, Korea Industrial Technology Association. Technology and Management, 11:36-39 
Small and medium-sized business of technology of innovation http://innobiz.net/com/main.asp?cate=1 (2011. 5. 30)

Know-how to establish a Technology Strategy, http://neohckim.blogspot.com/2010/04/blogpost_18.html (2011. 3. 23)

Technology push and market pull; coupling model, http://labspace.open.ac.uk/mod//resource/ view.php?id=349896(2011. 12. 10) 